\title{
A roadmap for sustainability assessment in the food supply chain
}

\author{
Verónica León Bravo, Antonella Moretto and Federico Caniato \\ School of Management, Politecnico di Milano, Milan, Italy
}

\begin{abstract}
Purpose - To develop a roadmap of sustainability practices and assessment mechanisms to advance in the sustainable supply chain (SSC) performance assessment in the food supply chain. The analysis is grounded on the contingency and stakeholder theories.

Design/methodology/approach - The study follows a multiple case study approach analyzing the sustainability practices implementation and assessment across different supply chain stages in the food industry in Italy. The set of cases comprises 12 companies in the fresh fruit and vegetables (FFV), and seven companies in the "Balsamic Vinegar of Modena" (BVM) supply chains.

Findings - The sustainability practices and assessment in each company in both supply chains according to their objectives are identified. Different stakeholder pressures for sustainability implementation and assessment are analyzed. The contingency factors that foster sustainability assessment are outlined as well. Finally, the study develops a roadmap with five levels of progress considering the groups of practices implemented and the type of assessment applied.

Practical implications - The roadmap is a decision-making tool for planning and monitoring progress on SSC performance along five possible levels of progress. While identifying the assessment mechanisms implemented for different kind of sustainability practices, companies can develop a strategy according to their aims and capabilities and stakeholder's expectations.

Originality/value - The novelties in this study are threefold. First, the roadmap with five levels of progress. Second, investigating two different food supply chains that allowed for a broader view regarding sustainability practices and assessment. Third, the adoption of stakeholder and contingency theories in SSC studies.
\end{abstract}

Keywords Sustainable supply chain, Sustainability practices, Sustainability assessment,

Sustainability roadmap, Food industry, Food supply chain

Paper type Research paper

\section{Introduction}

Companies in food industry face particular sustainability challenges regarding natural resources availability and consumption, food safety, waste management, unfair trade relationships, among others (FAO, 2014; European Commission, 2014; Paramanathan et al., 2004; Maloni and Brown, 2006). Consumers and other stakeholders' requirements regarding sustainability in this industry are among the most demanding (FAO, 2014), as they are paying growing attention to the industry social and environmental performance (Maloni and Brown, 2006). Unsurprisingly, food companies have started developing assessment policies, standards and reporting for sustainability performance according to the triple bottom line (i.e. environmental, social and economic) (Bloemhof et al., 2015; Trienekens et al., 2012) in the attempt of fulfilling such increasing stakeholder's demands.

Sustainability performance measurement is key to evaluate whether sustainability goals are achieved and stakeholder requirements met (Beske-Janssen et al., 2015; Grosvold et al.,

(C) Verónica León Bravo, Antonella Moretto and Federico Caniato. Published by Emerald Publishing Limited. This article is published under the Creative Commons Attribution (CC BY 4.0) licence. Anyone may reproduce, distribute, translate and create derivative works of this article (for both commercial and non-commercial purposes), subject to full attribution to the original publication and authors. The full terms of this licence may be seen at http://creativecommons.org/licences/by/4.0/legalcode

Roadmap for sustainability assessment in food SC (1) 
BFJ

123,13
2014; Schaltegger and Burritt, 2014; Taticchi et al., 2013). The sustainability assessment system (methods and techniques applied for measuring, monitoring and controlling sustainability) varies between firms in the supply chain according to the scope or range of issues to be measured and how are they measured, if they are (León-Bravo et al., 2020). Furthermore, as Gualandris et al. (2015) and Trienekens et al. (2012) posit, sustainability assessment and transparency vary between firms and between supply chains, according to intrinsic and extrinsic product attributes, firm capabilities, stakeholder's importance and supply chain integration.

Along these lines, roadmaps are recognized as useful tools for managers to establish priorities (Saritas and Aylen, 2010), set clear goals and define action plans to move organizations ahead in implementing a strategy (Ahmed and Sundaram, 2012; Saritas and Aylen, 2010). Many kinds of roadmaps are available in literature and, considering sustainability, they are presented as a method to support decision-making in the journey toward becoming more sustainable, by defining the steps to transform organizations and their supply chain (Paramanathan et al., 2004). As Moretto et al. (2018) summarized, several sustainability studies considered the road-mapping approach and resulted in interesting tools for decision-making and setting up progress agendas. In our study, we adopt this approach to investigate how companies in the food supply chain can progress in SSC performance assessment, thus providing an original contribution, given the lack of roadmaps specifically addressing this goal in literature.

Sustainability assessment is necessary to demonstrate that organizations and supply chains are attaining their performance objectives and improving relationships with their stakeholders (Freeman et al., 2010; Clarkson, 1995). Therefore, stakeholder theory (Freeman, 1984) is often adopted to investigate sustainability. Applied in sustainability studies, stakeholder theory suggests that companies implement sustainability practices mainly to respond to various stakeholder's pressures (Sarkis et al., 2011). In addition, as Gualandris et al. (2015) and Trienekens et al. (2012) indicate, there are distinctive elements in companies and supply chains that influence sustainability assessment. Hence, contingency theory (Sousa and Voss, 2008) will be adopted for identifying such elements that would provide further information for the roadmap for SSC assessment in the food supply chain. With these considerations in mind, this study aims to address the following research questions:

$R Q 1$. How can companies in the food supply chain progress in sustainability practices and assessment following a roadmap to achieve better SSC performance management?

$R Q 2$. How do different stakeholders influence the level of progress in the roadmap?

$R Q 3$. What are the contingent factors influencing the level of progress in the roadmap?

The study conducts the analysis of case studies in two supply chains, positioned at different stages of each chain. The research focuses on the Italian context where food industry is the second most important economic sector in terms of production volumes, import and export (Foodweb, 2015). The first set of cases regards the fresh fruits and vegetables (FF\&V) sector, being Italy first processor in this sector and third main exporter in the European Union (Eurostat, 2019). The second set of cases considers the Balsamic Vinegar of Modena's (BVM) sector: the BVM carries the PDO (i.e. Product Designation of Origin) and PGI (i.e. Product Geographical Indication) labels that have a specific link to the region where the product comes from (European Commission, 2017). The two supply chains are considered representative of several main features of the industry.

The rest of the paper is organized as follows. The conceptual background involving the description and definition of the road-mapping approach in sustainability studies is explained. Then, the research context and methodology are described; data analysis, findings and discussion are presented; finally, conclusions are drawn. 


\section{Conceptual background}

Sustainability practices and assessment in the food supply chain

Extant literature proposes numerous indicators to assess sustainability focusing on determining the areas to be monitored and identifying the measures or indicators, e.g. Aramyan et al. (2007), Varsei et al. (2014), Yakovleva (2007), Bloemhof et al. (2015), Arena and Azzone (2012). However, adopting too many indicators leads to the risk of making the assessment ineffective, especially if companies have no clear idea how different practices should be evaluated (Bourne et al., 2002). Genovese et al. (2017) also pointed out that the main challenge for companies is to identify which indicators to apply without overloading users with too many measures and avoiding information redundancies. Although performance assessment is well developed at the company level, when moving to a supply chain perspective the complexity grows and there is still need for further research (Maestrini et al., 2017). Previous research has shown that different actors in different stages of the food supply chain have different sustainability challenges and thus are implementing different practices requiring different tools to measure the performance (Golini et al., 2017; León-Bravo et al., 2019). Therefore, the need to adopt different measures for assessing sustainability in different stages in the chain increases the complexity to develop an effective assessment (Gualandris et al., 2015; Trienekens et al., 2012). Hence, literature shows a gap in providing companies and supply chains with tools to assess sustainability at different stages of the supply chain in a comprehensive and effective way.

To overcome the limitations of current literature, and to respond to the need of a decisionmaking tool for practitioners to be able to delineate and monitor progress in their SSC performance, first, we need to identify the sustainability practices and assessment approaches currently adopted in the food supply chain. Thus, for answering the first research question, we lever on the categorization proposed by León-Bravo et al. (2017) who compiled practices in the triple bottom line, specifically relevant to food industry (Table 1).

Furthermore, we need to review the existing sustainability assessment methods that food supply chains can apply for evaluating their sustainability efforts. Thus, for completing the constructs needed to answer the first research question, we group them into the following categories, consistently with literature insights:

(1) Non-structured assessment methods, when sustainability practices are assessed somehow, but the assessment is either related to a single economic or operative perspective or the data collected is not specifically used for evaluating sustainability (e.g. Varsei et al., 2014).

(2) Structured assessment methods, when there is a structured performance measurement system that is consolidated in the company with other existing measurement systems, such as the Global Reporting Initiative, Life Cycle Assessment, Codes of conduct or similar (e.g. De Toni and Tonchia, 2001).

(3) Certifications, i.e. formal performance assessment systems. They establish standard guidelines for all the actors adopting them, internationally recognized and compliance is certified by specialized third-parties (Trienekens et al., 2012; Gualandris et al., 2015). Some distinguished certifications schemes in food industry are British Retail Consortium (BRC), International Featured Standards Food (IFS Food), Fair Trade International (FTI).

\section{Roadmaps for sustainability}

A roadmap is defined by De Reuver et al. (2013), as " a detailed plan to guide progress toward a goal". According to Caritte et al. (2015), the purpose of roadmaps is guiding companies in the achievement of their goals, through the definition of a sequence of steps to be followed.
Roadmap for sustainability assessment in food SC 
BFJ 123,13
Sustainability dimension

Environment Natural Resources conservation (NRC)

Green processing, packaging and transportation (GPPT)

Social Health and Safety (H\&S)

Work and Human Rights (W\&HR)

Community

Economic Sustainable sourcing (SS)

Support SC partners
Example of practices

Soil conservation: forest and species conservation; prevent soil erosion and pollution, prevent loss of arable land and biodiversity, responsible farming methods (reducing fertilizer and pesticides), elimination of contaminant and pollutant agents

Water conservation: reducing water consumption, efficient water use, waste water re-use and recovery

Design, materials and packaging: design for reuse and recycling, material reuse and recycle, reducing packaging, using reusable or recyclable packaging

Waste management: reduce waste and hazardous materials, composting, producing renewable energy or animal feed with waste, damage compensation, recycling

Processing and transportation: reducing energy use, conservation of energy, reducing $\mathrm{CO}_{2}$ emissions and GHGs, reduce pollution, reduction of fuel consumption

Improved product quality, food safety, food security, traceability and transparency. Promotion of healthy life styles and local food. Safer warehousing and transportation

Better and safer working conditions that result in higher levels of motivation and productivity and less absenteeism. Training, education, advancement. Regular employment, elimination of illegal and child labor, respect of worker rights, gender equality, freedom of association

Donation, collaboration with NGOs, philanthropy, support economic development in local communities, job training, volunteering, childcare

Increasing supplier diversity, confidentiality, eliminating deception and impropriety, transparency, proper purchasing processes, supplier's labor programs, local sourcing that result in shorter leadtimes. Environmental and social considerations when selecting, monitoring and controlling suppliers

Profit sharing with actors in the upstream supply chain, premium price payment, support and monitoring for obtaining sustainability certification. Facilitate partners' access to markets, knowledge and technology transfer, fostering financing opportunities, information and expertise sharing

Table 1.

Sustainability practices in the food industry

Note(s): Adapted from León-Bravo et al. (2017)

Roadmaps orient companies toward goals and point to choices, looking into the future (Saritas and Aylen, 2010; Bolboli and Reiche, 2013). In this line, a roadmap could guide the decision-making process (Ahmed and Sundaram, 2012) as well as identify risks and opportunities for improvements, to enable reporting over time (Could and Wallbank, 2007).

As stated by de Abreu (2015) "a company has to address priorities among the various possibilities in achieving sustainability goals and develop an implementation plan [...]. A welldeveloped and detailed roadmap could therefore enable organizations to develop a plan in such uncertain and evolving topic often approached unsystematically". Another viewpoint by Ahmed and Sundaram (2012) addresses that many organizations are committed to transform their business with sustainable strategies, but they fail because they manage the business in a traditional way, observing only one or two pillars of the Triple Bottom Line (i.e. environmental, social and economic). Another major cause of failure is that managers often implement a series of initiatives without any overarching vision or plan that can be supported by a clear trajectory over the years (Lubin and Esty, 2010). 
Different types of roadmaps are proposed in literature. There are roadmaps oriented to the role of knowledge management (e.g. Robinson et al., 2006) or focused on specific functions such as human resource management and procurement (Vanegas, 2003), product design (Waage, 2007; Rocco, 2015) or project management (Chofreh et al., 2015). First attempts to consider the problem with a supply chain perspective are those presented by Valkokari et al. (2014), and Moretto et al. (2018), that focused on a particular industry (i.e. fashion).

More recently, literature has focused on roadmaps for sustainability due to the uncertainty of sustainability programs (Lin and Tseng, 2016). Nonetheless, it is still rare to find contributions in literature that clearly face the problem of identifying roadmaps with sustainability trajectories that embrace a supply chain perspective (Silvestre, 2015). Furthermore, while existing SSCM literature presents sustainability roadmaps as a useful tool for implementing sustainability practices within companies (e.g. Caritte et al., 2015; Bolboli and Reiche, 2013; Ahmed and Sundaram, 2012; Valkokari et al., 2014), the same approach is not yet adopted for the assessment of sustainability, specifically for food industry. This study aims at bridging this gap by focusing on the need of a decision-making tool, such as a roadmap, for guiding sustainability assessment adoption according to the company's strategies and capabilities.

\section{Stakeholder theory and contingency theory in sustainability studies}

Assessing sustainability efforts in supply chains is complicated given that different companies in the chain have different roles and capabilities, different goals and also perceive different stakeholder pressures for evaluating their performance (Genovese et al., 2017). Companies adopt certain practices with the aim to reach their objectives while observing stakeholder influences (Freeman et al., 2010). Accordingly, authors pointed out how different stakeholders' pressures and companies' capabilities frame the sustainability performance assessment strategy (Gualandris et al., 2015). Hence, stakeholder theory in our study will help explaining how companies implement certain sustainability practices and assessment for addressing such pressures.

For answering the second research question, we identified the stakeholders to be considered in the analysis. According to Freeman et al. (2010) stakeholders can be identified as primary (customers, employees, suppliers, communities, financiers) or secondary (competitors, media, government, special interest groups, consumer advocates groups). Sarkis et al. (2011) mentioned some internal and external stakeholders, the latter being supply chain partners and external organizations as the main influencers for the adoption of certain type of green practices. Bremmers et al. (2007) underlined that there is a high interdependence between companies and their primary stakeholders and this interdependence is more important for environmental management. These contributions are in line with Clarkson (1995) who described the primary stakeholders as investors, employees, customers, suppliers, government. They are the actors, individuals or organizations that perform any kind of transaction with the company. Instead, secondary stakeholders are not related in transactions with the company but are essential and can cause damage. Thus, according to literature, in this study we will analyze as primary stakeholders: customers, suppliers, employees and regulatory bodies; and community as the main secondary one.

Additionally, as pointed out in previous literature, there are contextual factors that influence sustainability assessment in supply chains (Gualandris et al., 2015; Trienekens et al., 2012). In their study, Sousa and Voss (2008) explained, grounded on the contingency theory, how companies adapt their behavior according to contextual factors in order to achieve better performance. Similarly, the development of a supply chain sustainability strategy needs to take into account the relevant contingent factors, in line with the contingency theory recommendations for corporate strategy (Hofer, 1975). Hence, contingency theory in our
Roadmap for sustainability assessment in food SC 
BFJ

123,13 study helps to identify the contextual elements that influence the adoption of sustainability assessment in the food supply chain.

The most frequent contingencies summarized by Sousa and Voss (2008) as the geographical context, firm size, strategic context and other organizational factors. For answering the third research question, we include the following contingencies in our study that are derived from literature: company size (Sousa and Voss, 2008), level of vertical integration (Trienekens et al., 2012; Gualandris et al., 2015), assessment complexity, stage of the supply chain and product type (Bourne et al., 2002; Genovese et al., 2017). In our study, the geographical location refers as well to the product type, since the Balsamic Vinegar of Modena is produced exclusively in a specific region, while fresh fruits and vegetables are produced and commercialized along the country.

Finally, it is crucial to understand the company's motives or objectives for implementing certain practices and assessment as elements driving the company's sustainability approach. On the basis of previous literature, the main objectives companies pursue when adopting sustainability are related first, to comply with regulations and legitimate their operations (Sarkis et al., 2011; León-Bravo et al., 2019), thus meeting the expectations of the regulatory bodies also mentioned in the stakeholder theory. Second, in the food sector companies deploy various sustainability efforts that may reduce costs, provide first mover advantages or improve company's image (Bremmers et al., 2007), that is to improve overall efficiency and effectiveness. Third, companies also pursue environmental and/or social aims with their sustainability practices and assessment for communicating, demonstrating their commitment and creating a good reputation with customers and the community in general (Wolf, 2014; Hoejmose et al., 2014). Thus, aligned with stakeholder theory, sustainability management has an effect on achieving traditional objectives such as reducing costs, increasing revenues, building social capital and capturing knowledge (Hörisch et al., 2014).

\section{Research methodology}

This study followed and applied an inductive case-based methodology (Gioia et al., 2013), with the purpose to design a new roadmap for sustainability practices and assessment in the supply chain, and hence develop new knowledge grounded on case study evidences. Two types of products are studied: fresh fruits and vegetables (FF\&V) and Balsamic Vinegar of Modena's (BVM), thus observing different supply chain features, sustainability practices and type of assessment adopted. On one side, the FF\&V chain is characterized by high perishability, high product variety and packaging sizes, long production times, high set-up costs. On the other side, the BVM has strict certification requirements concerning production, processing and bottling, thus certain behaviors in relation with respect to the environment, attention to community and territory are expected. Both supply chains involve actors with different characteristics, locations and business objectives and they also deal with stakeholder pressures as quality expectations and compliance with certification requirements. For this study, companies were selected because of their sustainability approach set up within different axes of action: specific sustainability strategy, development of organic product lines, higher attention to product quality and traceability, sustainability reporting, etc. The set of cases includes companies of different sizes and levels of vertical integration (Trienekens et al., 2012) as well as operating at different stages of the chain (Gualandris et al., 2015; Arena and Azzone, 2012; León-Bravo et al., 2019).

In the FF\&V the final sample is composed by 12 companies while in the Balsamic Vinegar of Modena supply chain, three industry experts were interviewed in a first data collection wave, then a set of seven companies were selected, covering most of the activities in the supply chain (See Table 2, Figures 1 and 2).

Data were collected via semi-structured interviews and from secondary sources as websites, online news publications and when available, sustainability reports, thus 


\begin{tabular}{llcl}
\hline Case & Product & $\begin{array}{c}\text { Sales }[\mathrm{mln} \\
€ / \text { year }]\end{array}$ & Supply chain stage \\
\hline A & Fresh fruit & 1 & Grower \\
$\mathrm{B}$ & Fresh fruit and vegetables & 2.100 & Grower, Processor, Wholesaler \\
$\mathrm{C}$ & Fresh vegetables & 32 & Grower, Processor, Wholesaler \\
$\mathrm{D}$ & Fresh fruit and vegetables & 230 & Grower, Processor, Wholesaler \\
$\mathrm{E}$ & Fresh fruit & 34 & Grower, Processor, Wholesaler \\
$\mathrm{F}$ & Juices and canned vegetables & 400 & Processor \\
$\mathrm{G}$ & Dried fruit and juices & 110 & Processor \\
$\mathrm{H}$ & Frozen vegetables & $1,684^{*}$ & Processor \\
$\mathrm{I}$ & Fresh fruit & 14 & Wholesaler \\
$\mathrm{J}$ & All & 12.400 & Retailer \\
$\mathrm{K}$ & All & 200 & Wholesaler, Retailer \\
$\mathrm{L}$ & All & 1.000 & Retailer \\
$\mathrm{M}$ & Grape grower, Must producer and concentrator, & 21 & Focal Company \\
& Ager, Bottler & & \\
$\mathrm{N}$ & Grape grower, Must producer and concentrator, & 15 & Focal Company \\
& Ager, Bottler & & \\
$\mathrm{O}$ & Manufacturer, Ager, Bottler & 100 & Focal Company \\
$\mathrm{P}$ & Manufacturer, Ager, Bottler & 5 & Focal Company \\
$\mathrm{Q}$ & Must producer & 12 & First tier supplier \\
$\mathrm{R}$ & Grape grower, Must producer & 100 & Second tier supplier \\
$\mathrm{S}$ & White vinegar producer, Manufacturer, Ager, & 110 & Focal Company \\
& Bottler & &
\end{tabular}

Note(s): *Value includes several product categories among which FFV

Roadmap for sustainability assessment in food SC

205

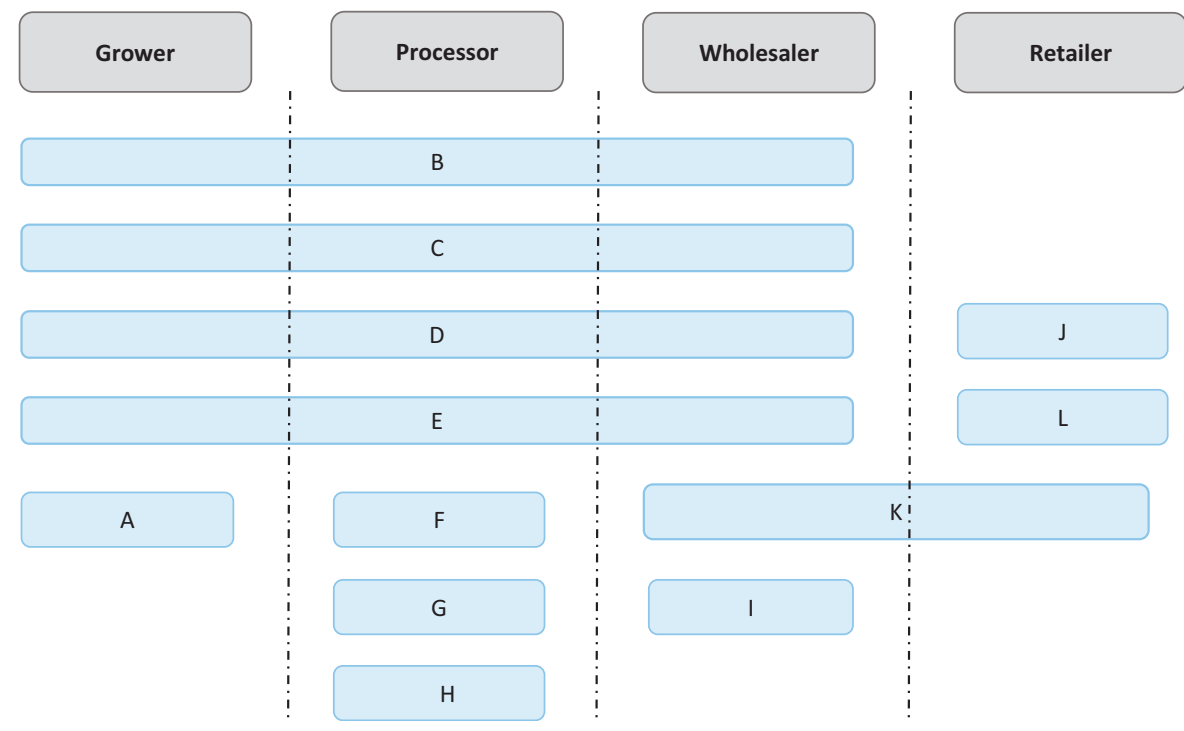

Table 2.

Set of cases under analysis

Figure 1.

Cases distribution along the FF\&V supply chain

increasing validity. Beyond direct interviews, to deal with any potential bias, information was also triangulated with company visits and the industry expert's insights (Voss et al., 2002; Yin, 2009). Some of the companies also provided internal documentation that reported sustainability projects and results. 
BFJ
123,13

\section{6}

Figure 2.

Cases distribution along the BVM supply chain

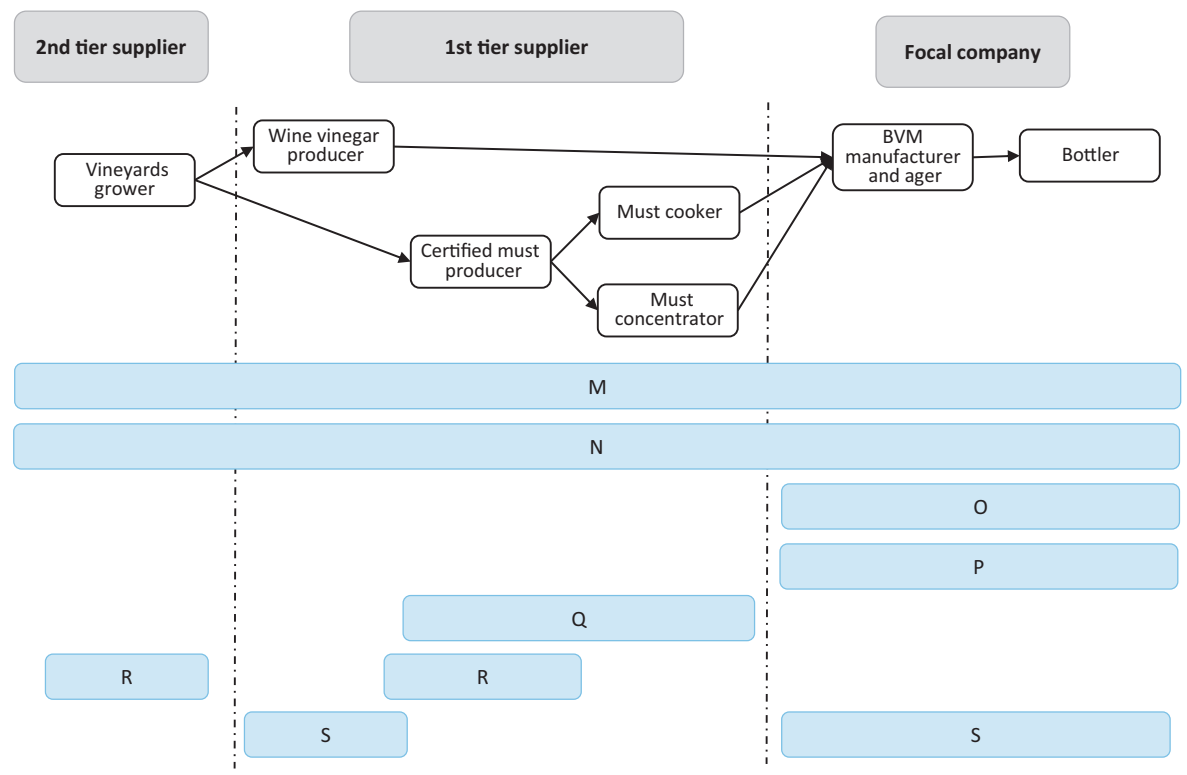

The interviews followed a semi-structured approach allowing the interviewees to develop their ideas, in this way the researchers were able to take advantage of emergent themes and unique case features (Eisenhardt, 1989). Three researchers developed the interview protocol based on the literature review, and then it was validated and updated as interviews went on. Two or three researchers conducted the interviews and transcribed the data. Researchers gathered information on sustainability practices, assessment methods, stakeholder pressures and contingencies determining the company's sustainability approach. Interviews were coded according to the constructs derived from the literature and presented in the conceptual background section.

Data analysis was performed in five steps: within case, cross case, cross-stage, cross-chain and theory building stage. Accordingly, first, all the constructs considered in the study were analyzed within each case for identifying the sustainability practices implemented in each company and the assessment performed, if any (see examples in Table 3). Second, a crosscase analysis involved the comparison of companies' behavior in terms of practices and assessment implementation, for pattern identification in cases in the same supply chain stage. A cross-stage analysis involved the comparison of sustainability practices and assessment applied across the different supply chain stages studied, as well as the identification of common elements that could determine the use or not of SSC assessment. The cross-chain analysis allowed the comparison between FF\&V and BVM supply chains, thus highlighting similarities and differences. Finally, the theory building stage involved combining data and theory for designing a roadmap for sustainability practices and assessment mechanisms.

\section{Results and discussion}

Designing a roadmap for sustainability assessment in the food industry

On the basis of the case analysis, by observing sustainability practices implemented and assessment applied, if any, in each company of both supply chains, different approaches are identified. 


\section{Topic \\ Sustainability practices}

Sustainability assessment

\section{Quote}

"Regarding sustainability, we optimize the use of space in the truck, optimize travelling routes, optimize combination of product families per trip, for example FFV and with canned goods, it contaminates less" (Case K)

"product packaging is made of biodegradable materials that can also be reused by consumers and not wasted immediately" (Case B)

"We work for environmental sustainability taking care of an efficient use of resources in our facilities, for instance, we have recovery systems (heat and steam) for fruit pasteurization, also, we recover and reuse of hot water for cleaning purposes" (Case G)

"We are working together with suppliers for the use of recycled or biodegradable plastic, we also support producers to develop projects for composting through our fair-trade program." (Case I) "we are not really focused on reducing our environmental impact because we believed we already have 0 impact thanks to our local production policy: buying raw material from $0 \mathrm{~km}$ suppliers have impacted greatly on eliminating emissions"

"Employees are family, if they need some help, the family is there for them. If they feel home, they will be happy, work better and be more productive [...] This is good for them and for the company as we gain a lot in visibility and efficiency" (Case P)

"Regarding sustainability we have several projects in place, for example, we joined a consortium for energy generation from renewable sources, and we get competitive prices. Also, to be more sustainable we implemented a filtering system for the wastewaters, installed LED lighting bulbs. Moreover, we invest in employees training about hygiene, English language, and competitive business practices" (Case S)

[For water consumption control] "we installed sensors close to the plants for monitoring the amount of water the plants receive and if it is enough for them" (Case A)

"We do not measure plenty of practices, it would be certainly overwhelming! [...] we [processors] should not bear all the responsibility and costs" (Case B)

"We have a control room that registers and monitors the use of water, energy and methane, continuously... it is a quite evolved system" (Case G)

"Potentials for performance measurement are huge, we started with the use of resources (energy, water), monitoring and communicating to everyone in the company. Periodically we analyze the consumption and discuss how to reduce them. But still, there is a lot to do with all the information and indicators we already have" (Case G)

"Each POS controls and monitors the packaging waste generated per product family per SKU. Weekly revision of waste reduced and causes, we've improved our performance reducing $50 \%$ of waste!" (Case K)

"We do believe that certificates have 'power' to create customer's trust and create the possibility to reinforce supplier monitoring" (Case N)

"Every day some employees must fill in the system with many data, and at the end of the year, sometimes data are combined [... . we know it is important to look not only at revenues, profit and ROI because "revenues and profit do not look at the future!, but in practice, it is difficult to do something else" (Case N)

[performance measurement] is really basic, we manage few financial indicators, and when a customer wants to know about our sustainability initiatives and performances, we need to retrieve different data stored in our database, but they are not evaluated and monitored constantly" (Case P)

"we developed our own sustainability report since 2014, we are the first company in the sector to publish a sustainability report" (Case S)

Stakeholder requirements
"We have plenty of certifications, depending on the requirements of each buyer in Italy and abroad" "certifications allow as to show our consumers they are safe, they [certifications] legitimate us" (Case B)

Our clients [large retailers] require also the compliance with this type of certifications. We audit our supplier every 2 years to ensure everyone is aligned with those principles" (Case G)

"Is also important to communicate internally what the amount of $\mathrm{CO}_{2}$ reduced means in terms of number of trees, or any other example that makes people/staff aligned and committed with our impact" (Case K)

"the main performance to observe [regarding sustainability] is quality. Even if quality is not paid, but is asked by the customer, and definitely without quality we do not work!" (Case Q)
Roadmap for sustainability assessment in food SC

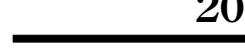


$\mathrm{BFJ}$

123,13

208

We noticed that companies in both supply chains apply sustainability practices and assessment mechanisms according to the stakeholders they deal with or to the objectives they have. For instance, Cases B and G in the FF\&V supply chain apply "Health and Safety" practices, as case G explained: "soil is our most valuable resource, we depend on it for everything, we would not be here without a healthy soil". In this supply chain, the assessment also includes the certification adoption beyond regulations with an aim of improving their environmental image. Instead, in the BVM supply chain, practices in the "Green processing packaging and transportation" category aim at improving efficiency. Another commonality was in the companies that declared to have a defined sustainability strategy and thus, their sustainability practices respond to a sustainability mission or vision. For instance, Cases D, E, J, K and H had practices for "Sustainable sourcing", "Supporting SC partners", "Green processing, packaging and transportation" as part of their strategy. However, the assessment in these cases does not necessarily exist or it is non-structured. Likewise, Cases N, O and P implement several practices following their sustainable strategy in the environmental and social dimensions, though such practices are either not assessed or just in a non-structured way. This heterogeneous assessment is consistent with previous literature (Leon Bravo et al., 2020). Authors have mentioned that when the number of sustainability issues covered increases, the complexity of evaluation and verification tends to increase too (Gualandris et al., 2015).

Furthermore, being the FF\&V and BVM supply chains highly complex (i.e. different sizes, locations, products, strategies, regulations), the assessment is not straightforward. The level of formalization, i.e. definition of measurement criteria, frequency, cost of the measurement, obligations/responsibilities for each measurement and integration (De Toni and Tonchia, 2001), is different among the practices implemented and among type of companies. Companies apply a more structured (or certification) kind of assessment when the practices are regulated and they need to report the results or when a particular product is to be promoted (Schmitt et al., 2017; Varsei et al., 2014).

Analyzing and contrasting the approaches across companies in both supply chains, we recognized five different levels of progress according to the practices adopted and the type of assessment applied. These five levels of progress delineate a roadmap that also considers the main company's objectives for implementing SSC assessment, as well as the stakeholders and contingencies related. Appendix 1 shows the detailed roadmap development with the list of sustainability practices and cases in each level. Furthermore, Table 4 summarizes the levels of progress in the roadmap that are described below:

(1) Conformance. The first level represents the combination of practices and assessment that companies apply to meet regulatory requirements. These practices are assessed in a structured manner, the objective is compliance with the regulatory bodies and when the assessment reaches the level of certification is because of the product type (FF\&V supply chain) and if the company is somehow vertically integrated.

(2) Initial. The second level involves companies that implement a wider set of sustainability practices beyond mandatory ones, responding to the pressures of several stakeholders, among which the main ones are the consumers and the community. Nonetheless, assessment remains either non-applied or it is done in a nonstructured way, mainly because of company size and because performing any type of measurement is considered highly complex. In this step companies are motivated to improve efficiency. In these cases, companies devote their efforts to keeping their operations efficient and make the best use of their practices without defining a sustainability strategy per se. 


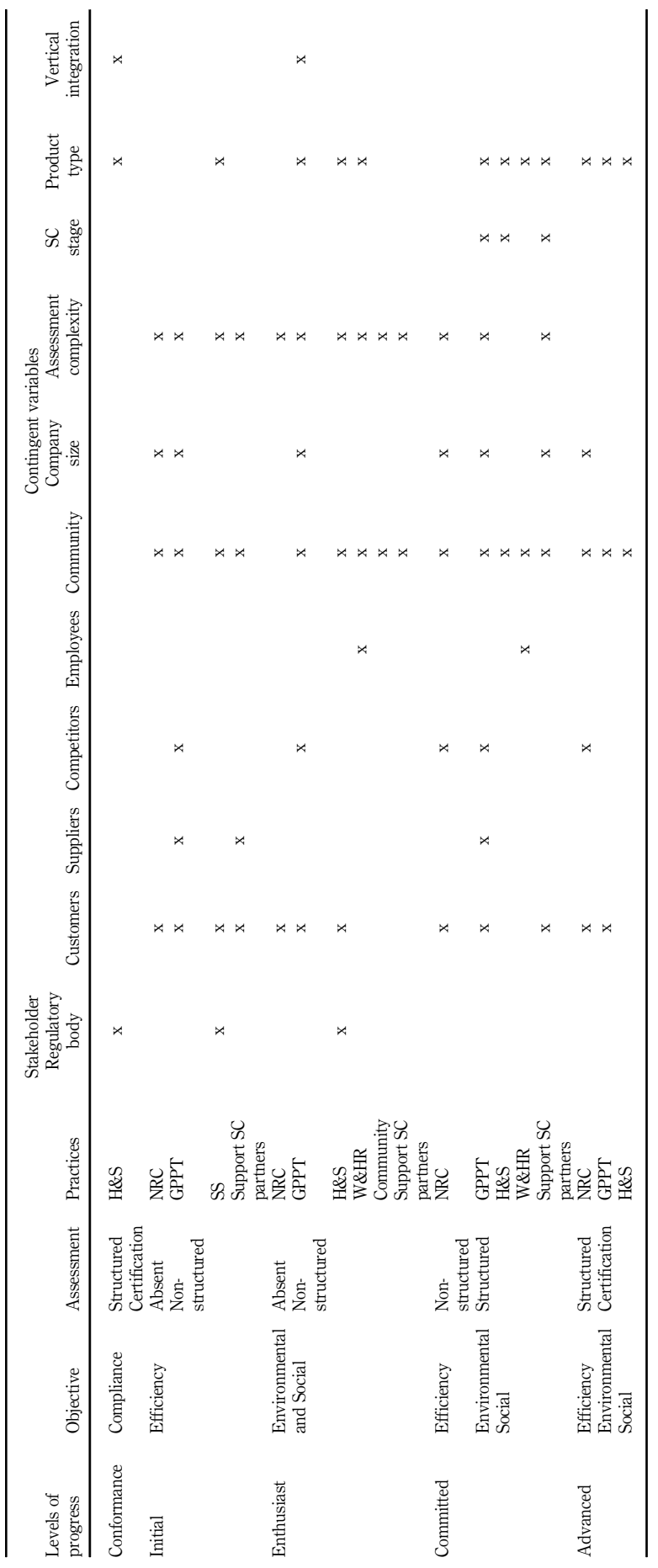

Roadmap for sustainability assessment in food SC

209

Table 4. Levels of progress in the roadmap, stakeholder and contingent variables related (summary) 
BFJ

123,13

\section{0}

(3) Enthusiast. While progressing in their sustainability journey, companies can decide to implement a broader and diversified set of sustainability practices with the objective of improving their environmental and social footprint. This approach was observed specially in some cases in the BVM supply chain. In this level, assessment is not yet implemented or is done in a rather qualitative and non-structured way, mainly because companies find sustainability assessment highly complicated. Companies face pressures from varied stakeholders, as well. In these cases, companies still struggle with defining a clear sustainability strategy and with keeping track of measurements.

(4) Committed. Advancing in the roadmap, in the fourth level of progress are the companies adopting a sustainability approach aimed not only at an efficiency objective but also environmental and social image. These cases do assess their sustainability practices in a more structured way, responding to several stakeholders among which community is the main one. The contingencies supporting this level in the roadmap vary. It is seen that several companies in the FF\&V (product type) are committed and also the larger companies (company size) in both chains.

(5) Advanced. The level of the roadmap describes companies that have embedded the sustainability assessment in their company strategy, hence, sustainability practices are consistently evaluated (in a structured way) and improved, and when possible, also certified. These companies aim simultaneously at efficiency, environmental and social image, responding mainly to the community expectations. These cases are commonly found in the FF\&V supply chain (product type), where also is the largest company in the sample (company size). In addition, a specific and distinctive case is company A, the smallest in the set of cases, that adopt a strategy highly committed with sustainability, tough is not the common approach in small companies, as will be discussed in the following section.

Therefore, according to each company's objectives and capabilities, the implementation of sustainability practices and assessment can be planned by adopting this roadmap. The cumulative steps of the roadmap proposed in this study, unlike previous roadmaps in literature, are not rigid and do not follow a strict timeline, since a company can set up a progress plan based on the combination of practices and assessment it decides to implement, according to the stakeholder requirements and the relevant contextual factors, with its own speed. This is a novelty in our study as the roadmap would be useful for companies to set up its own path. For instance, if there is a new regulation, the company will need to comply and demonstrate its acquiescence, often with a report or certification, thus locating this practice in the conformance step. In other situations, when a company has already several practices in place, not only mandatory but also for gaining efficiency, it can monitor its current objectives (e.g. keep track of operations, communication and reporting) and its current assessment. Then, the company can decide if maintaining its state or progress to a more advanced step, and thus, evolve its objectives and consequently its assessment systems.

\section{The stakeholder influences on the roadmap for sustainability assessment}

Increasing stakeholders' demands for better sustainability performance have triggered the interest on sustainability performance measurement in both supply chains analyzed in this study. According to the stakeholder theory and as summarized by Freeman et al. (2010), the variety of sustainability practices and assessment types implemented in these two food supply chains in Italy explain how companies respond to pressures by diverse stakeholders. Findings in our study evidenced that companies deploy varied sustainability practices intending first to meet regulatory requirements, i.e. respecting the policies delineated by the 
regulation bodies in the food sector (governments, EU labeling, consortia, etc.). For instance, for the PDO and PGI labels in the BVM supply chain, companies must respect the policies established by the labeling organizations and by the BVM Consortium. In addition, companies implement sustainability to attract new consumers that value a wider range of sustainability initiatives, but first of all to preserve business relationships with large retailers that more and more require sustainability attributes.

Additionally, some companies implement philanthropic initiatives, while others are more oriented to safer and healthier food in both supply chains, which is mainly required by the community in general. Such practices could be costly and complex to implement but are also somewhat foreseen by the consumer. Therefore, companies are driven also by the market pressure to demonstrate commitment to environmental and social dimensions.

In line with Clarkson (1995), companies are generating assessment data and demonstrate more attention to issues considered more important. Hence, the pressure perceived from a stakeholder that is considered a priority (e.g. customers, community, regulatory body) justifies the practice to be implemented and consequently monitored (see Table 4). Besides, when the issue is not considered crucial to be managed, i.e. the stakeholder is not as important as others are, as Clarkson (1995) argued, the company would not generate assessment data at all.

As in previous literature, also in our study the stakeholder theory reinforces how companies deploy sustainability with the aim to respond to stakeholder expectations and to keep and extend their competitive advantage (Sarkis et al., 2011); hence, pressures from different stakeholders are considered in the roadmap. Therefore, considering the stakeholders that have a role for triggering the application of certain sustainability practices in a certain level of progress in the roadmap is a contribution of our study. In this way, companies that perceive a particular pressure from stakeholders could define the path to progress in their sustainability assessment accordingly.

\section{Contingencies impact on the roadmap for sustainability assessment}

From the case analysis, a set of contingencies are found to impact the sustainability assessment in the FF\&V and BVM supply chains: company size, supply chain stage, assessment complexity, product type and level of vertical integration.

Smaller companies are found to face more challenges for implementing a more structured sustainability assessment due to, mainly, their lack of resources, but also their limited capabilities or expertise related to performance measurement. Both in the FF\&V and BVM supply chains, smaller companies tend to stay in the conformance or initial level, focused on compliance or on efficiency. With the exception of Case A that adopts a more advanced approach toward sustainability practices and assessment. Commonly, smaller companies are in a starting point of performance assessment by keeping track of their operations or communicating their initiatives.

Along with company size, the supply chain stage also appears to determine specific combinations of SSC practices and assessment. Specifically, retailers apply a distinctive approach allegedly because they are closer to the market and have the means and capabilities to measure their sustainability practices (e.g. cases F, K, L), they are in the committed level of the roadmap with their GPPT, W\&HR and Support to SC partners practices. However, it is interesting to note that companies in the other supply chain stages, as case $\mathrm{H}$ (processor), are also combining practices and assessment in the committed level of the roadmap, but those are observed as exceptional behaviors rather than a commonality in that particular supply chain stage.

Furthermore, the complexity that companies face when evaluating sustainability is an element that influences the implementation of sustainability assessment. Companies in both
Roadmap for sustainability assessment in food SC 
BFJ

123,13

supply chains perceive SSC assessment to be complex and resource consuming. Hence, even if varied sustainability practices are implemented, as the assessment is too complex to be managed, it remains unstructured or even absent in many companies, at the initial and enthusiast levels in the roadmap. In line with previous literature, the identification and selection of measures demand efforts that could be overloading when they require overly sophisticated or difficult information (Bourne et al., 2002; Genovese et al., 2017). Thus, companies are either not evaluating their practices (absent), initially establishing a performance assessment system (non-structured), or at most, integrating sustainability in their existing systems (structured) that do not alter daily operations.

Additionally, we observed that product type influences the more advanced levels of progress in the roadmap. Several companies in the BVM supply chain adopted a combination of practices and assessment in the enthusiast level, while cases in the FFV deployed a more committed or advanced approach with objectives of efficiency, environmental and social image, and an intention of structuring their sustainability assessment into their strategy. This difference relates to a greater interest in the FFV supply chain for communicating and demonstrating its engagement with sustainability. Companies in this chain are said to perceive higher pressures from community and consumers for higher sustainability performance.

Another contingency factor found in the case analysis is the vertical integration. Companies in both supply chains that have higher levels of integration (e.g. cases B, C, E, M, N) are able to spread practices and assessment across operations, hence, they tend to deploy a more formal measurement system. As Trienekens et al. (2012) and Gualandris et al. (2015) explained, in vertical organizations, traceability could be more easily implemented and sustainability assessment could be more structurally formalized through certifications. This was the case of vertically integrated companies in the conformance or enthusiast level of progress in the roadmap. Interviewee in Case $\mathrm{N}$ declared: "the decision to be integrated is the most sustainable decision". Companies complied with regulatory practices on one level, and adopted a broader range or sustainability practices on the other level.

Thus, the contingency theory in our study helps to identify and describe the elements or contingencies that motivate sustainable supply chain assessment as well as the behavior in each specific phase on the roadmap.

\section{Conclusions}

The aim of this study is to design a roadmap for SSC performance assessment in the food supply chain, analyzing 21 cases in two supply chains, FF\&V and BVM, considering companies in four stages of the supply chain. The study is grounded on stakeholder theory considering how companies deal with expectations from different stakeholders to implement and to assess sustainability. Moreover, leveraging on contingency theory the main elements influencing the sustainability practices and assessment are identified. In particular, the roadmap proposed in our study identifies five levels of progress, considering the variety of sustainability practices implemented in different stages of the supply chain, as well as the diverse assessment methods used to evaluate and monitor such practices.

The contributions of the study are threefold. First, the sustainability assessment roadmap provides a guide to plan and implement progress toward SSC performance management. Second, by adopting a stakeholder theory perspective, the study identifies how different actors influence sustainability implementation and assessment, and consequently drive the use of the roadmap. Third, the study levers on the contingency theory to identify the contextual elements that influence the adoption of sustainability practices and the progress on the roadmap. 
These contributions are innovative and relevant, since studies that propose a decisionmaking tool to develop sustainability assessment beyond the metrics definition are lacking (Gualandris et al., 2015; León-Bravo et al., 2020). In our study, we observed that companies in two supply chains indeed try to assess their sustainability, however, for advancing in their SSC assessment and performance management, companies can adopt different combination of practices and assessments according to the main stakeholders' pressures and influenced by one or more contingency. As Freeman et al. (2010) argued, companies need to manage trade-offs when facing multiple stakeholder's expectations and thus, companies would require to find the appropriate approach for dealing with stakeholders while getting benefits from their sustainability efforts (Sarkis et al., 2011). Also, companies are assessing their sustainability efforts in response to what they consider to be most important stakeholders (e.g. regulatory bodies, consumers, community, employees, suppliers, competitors) while pursuing specific objectives. Sustainability assessment is varied, thus also confirming that companies choose a certain level of sustainability progress according to their goals, i.e. compliance to regulations, efficiency, environmental and social image.

A further contribution regards the analysis of two supply chains. One related to a general consumption type of product: $F F \& V$, with its own characterizing features of short-life span, quality variation, freshness requirements. The second involves a certified processed product supply chain: BVM, characterized by particular features regarding production, regulations and market (Taticchi et al., 2013; León-Bravo et al., 2020). Observing two different food supply chains allowed for a broader view of the industry approach to sustainability thus leading to more general and robust findings.

This study is also of interest for practitioners. The availability of a roadmap for SSC performance measurement can be valuable for managers who face the challenge to implement and assess sustainability, taking into account stakeholders' requirements and contextual factors. The roadmap depicts five levels of progress that a company can plan and implement according to its objectives and the stakeholders' expectations that are considered a priority, while identifying the assessment mechanisms that can be implemented considering the relevant contingent factors according to the company characteristics and capabilities.

The study has some limitations that open opportunities for further research. The analysis was concentrated in a particular country, thus, it could be interesting to validate the results in a broader geographical context. Also, future research might be oriented to either compare results with other products or to validate current results through a statistically significant sample, for improving generalizability.

\section{References}

Ahmed, M.D. and Sundaram, D. (2012), "Sustainability modelling and reporting: from roadmap to implementation”, Decision Support Systems, Vol. 53 No. 3, pp. 611-624.

Aramyan, L.H., Lansink, A.G.O., Van Der Vorst, J.G. and Van Kooten, O. (2007), "Performance measurement in agri-food supply chains: a case study", Supply Chain Management: An International Journal, Vol. 12 No. 4, pp. 304-315.

Arena, M. and Azzone, G. (2012), "A process-based operational framework for sustainability reporting in SMEs", Journal of Small Business and Enterprise Development, Vol. 19 No. 4, pp. 669-686.

Beske-Janssen, P., Johnson, M.P. and Schaltegger, S. (2015), "20 years of performance measurement in sustainable supply chain management-what has been achieved?", Supply Chain Management: An international Journal, Vol. 20 No. 6, pp. 664-680.

Bloemhof, J.M., van der Vorst, J.G., Bastl, M. and Allaoui, H. (2015), "Sustainability assessment of food chain logistics", International Journal of Logistics Research and Applications, Vol. 18 No. 2, pp. 101-117.
Roadmap for sustainability assessment in food SC 
$\mathrm{BFJ}$ 123,13

\section{4}

Bolboli, S. and Reiche, M. (2013), "A model for sustainable business excellence: implementation and the roadmap", The TQM Journal, Vol. 25 No. 4, pp. 331-346.

Bourne, M., Neely, A., Platts, K. and Mills, J. (2002), "The success and failure of performance measurement initiatives: perceptions of participating managers", International Journal of Operations and Production Management, Vol. 22 No. 11, pp. 1288-1310.

Bremmers, H., Omta, O., Kemp, R. and Haverkamp, D.J. (2007), "Do stakeholder groups influence environmental management system development in the Dutch agri-food sector?", Business Strategy and the Environment, Vol. 16 No. 3, pp. 214-231.

Caritte, V., Acha, S. and Shah, N. (2015), "Enhancing corporate environmental performance through reporting and roadmaps", Business Strategy and the Environment, Vol. 24 No. 5, pp. 289-308.

Chofreh, A.G., Goni, F., Shaharoun, A.M. and Ismail, S. (2015), "A review on sustainability transformation roadmaps using project management methodology”, Advanced Science Letters, Vol. 21 No. 2, pp. 133-136.

Clarkson, M.E. (1995), "A stakeholder framework for analyzing and evaluating corporate social performance”, Academy of Management Review, Vol. 20 No. 1, pp. 92-117.

Could, C. and Wallbank, C. (2007), "Sustainability roadmap: an occupier's journey", Advance, New Knowledge First, Jones Lang LaSalle, available at: https://www.gbca.org.au/docs/ Sustainability \%20Roadmap \%20An\%20Occupiers\%20Journey\%20JLL.pdf (accessed February 2020).

de Abreu, M.C.S. (2015), "Perspectives, drivers, and a roadmap for corporate social responsibility in the textile and clothing industry", Roadmap to Sustainable Textiles and Clothing, Springer, Singapore, pp. 1-21.

De Reuver, M., Bouwman, H. and Haaker, T. (2013), "Business model roadmapping: a practical approach to come from an existing to a desired business model", International Journal of Innovation Management, Vol. 17 No. 1, 1340006.

De Toni, A. and Tonchia, S. (2001), "Performance measurement systems-models, characteristics and measures", International Journal of Operations and Production Management, Vol. 21 Nos 1/2, pp. 46-71.

Eisenhardt, K.M. (1989), "Building theories from case study research", Academy of Management Review, Vol. 14 No. 4, pp. 532-550.

European Commission, Agricultural and Rural Development (2014), “The EU's common agricultural policy (CAP): for our food, for our countryside, for our environment”, available at: http://ec. europa.eu/agriculture/cap-overview/2014_en.pdf.

European Commission Agricultural and Rural Development (2017), "EU quality logos", available at: https://ec.europa.eu/agriculture/quality/schemes_en Last access (accessed 3 November 2017).

Eurostat (2019), "The fruit and vegetable sector in the EU - a statistical overview", available at: http:// ec.europa.eu/eurostat/statistics-explained/index.php/The_fruit_and_vegetable_sector_in_the_ EU_-_a_statistical_overview (accessed 27 February 2020).

FAO (Food and Agricultural Organization of the United Nations) (2014), "The state of food and agriculture 2014", available at: http://www.fao.org/publications/sofa/2014/en/?\%DC\%19-\%07=.

Foodweb (2015), "Ecco il bilancio 2014 e le previsioni 2015 dell'industria alimentare Italiana", available at: https:/www.foodweb.it/2015/01/ecco-il-bilancio-2014-e-le-previsioni-2015-dellindustriaalimentare-italiana/ (accessed 21 January 2020).

Freeman, R. (1984), Strategic Management: A Stakeholder Approach, Pitman, Boston.

Freeman, R.E., Harrison, J.S., Wicks, A.C., Parmar, B.L. and de Colle, S. (2010), Stakeholder Theory: The State of the Art, Cambridge University Press, Cambridge.

Genovese, A., Morris, J., Piccolo, C. and Koh, S.L. (2017), "Assessing redundancies in environmental performance measures for supply chains", Journal of Cleaner Production, Vol. 167, pp. 1290-1302. 
Gioia, D.A., Corley, K.G. and Hamilton, A.L. (2013), "Seeking qualitative rigor in inductive research: notes on the Gioia methodology", Organizational Research Methods, Vol. 16 No. 1, pp. 15-31.

Golini, R., Moretto, A., Caniato, F., Caridi, M. and Kalchschmidt, M. (2017), "Developing sustainability in the Italian meat supply chain: an empirical investigation", International Journal of Production Research, Vol. 55 No. 4, pp. 1183-1209.

Grosvold, J., Hoejmose, U.S., Roehrich, K. and J. (2014), "Squaring the circle: management, measurement and performance of sustainability in supply chains", Supply Chain Management: An International Journal, Vol. 19 No. 3, pp. 292-305.

Gualandris, J., Klassen, R.D., Vachon, S. and Kalchschmidt, M. (2015), "Sustainable evaluation and verification in supply chains: aligning and leveraging accountability to stakeholders", Journal of Operations Management, Vol. 38, pp. 1-13.

Hoejmose, S.U., Roehrich, J.K. and Grosvold, J. (2014), "Is doing more doing better? The relationship between responsible supply chain management and corporate reputation", Industrial Marketing Management, Vol. 43 No. 1, pp. 77-90.

Hofer, C.W. (1975), "Toward a contingency theory of business strategy", Academy of Management Journal, Vol. 18 No. 4, pp. 784-810.

Hörisch, J., Freeman, R.E. and Schaltegger, S. (2014), "Applying stakeholder theory in sustainability management: links, similarities, dissimilarities, and a conceptual framework", Organization and Environment, Vol. 27 No. 4, pp. 328-346.

León-Bravo, V., Caniato, F., Caridi, M. and Johnsen, T. (2017), "Collaboration for sustainability in the food supply chain: a multi-stage study in Italy", Sustainability, Vol. 9 No. 7, p. 1253.

León-Bravo, V., Caniato, F. and Caridi, M. (2019), "Sustainability in multiple stages of the food supply chain in Italy: practices, performance and reputation", Operations Management Research, Vol. 12 No. 1, pp. 40-61.

León-Bravo, V., Caniato, F. and Caridi, M. (2020), "Sustainability assessment in the food supply chain: study of a certified product in Italy", Production Planning and Control, pp. 1-18, doi: 10.1080/ 09537287.2020.1744761.

Lin, Y.H. and Tseng, M.L. (2016), "Assessing the competitive priorities within sustainable supply chain management under uncertainty", Journal of Cleaner Production, Vol. 112, pp. 2133-2144.

Lubin, D.A. and Esty, D.C. (2010), “The sustainability imperative”, Harvard Business Review, Vol. 88 No. 5 , pp. $42-50$.

Maestrini, V., Luzzini, D., Maccarrone, P. and Caniato, F. (2017), "Supply chain performance measurement systems: a systematic review and research agenda", International Journal of Production Economics, Vol. 183, pp. 299-315.

Maloni, M.J. and Brown, M.E. (2006), "Corporate social responsibility in the supply chain: an application in the food industry", Journal of Business Ethics, Vol. 68 No. 1, pp. 35-52.

Moretto, A., Macchion, L., Lion, A., Caniato, F., Danese, P. and Vinelli, A. (2018), "Designing a roadmap towards a sustainable supply chain: a focus on the fashion industry", Journal of Cleaner Production, Vol. 193, pp. 169-184.

Paramanathan, S., Farrukh, C., Phaal, R. and Probert, D. (2004), "Implementing industrial sustainability: the research issues in technology management", R\&D Management, Vol. 34 No. 5, pp. 527-537.

Robinson, H.S., Anumba, C.J., Carrillo, P.M. and Al-Ghassani, A.M. (2006), "STEPS: a knowledge management maturity roadmap for corporate sustainability", Business Process Management Journal, Vol. 12 No. 6, pp. 793-808.

Rocco, C. (2015), "Aspects to enhance environmental sustainability in industry: a brief roadmap", Sustainability: The Journal of Record, Vol. 8 No. 5, pp. 254-260.

Saritas, O. and Aylen, J. (2010), "Using scenarios for roadmapping: the case of clean production", Technological Forecasting and Social Change, Vol. 77 No. 7, pp. 1061-1075.
Roadmap for sustainability assessment in food SC 
BFJ

123,13

\section{6}

Sarkis, J., Zhu, Q. and Lai, K.H. (2011), "An organizational theoretic review of green supply chain management literature", International Journal of Production Economics, Vol. 130 No. 1, pp. 1-15.

Schaltegger, S. and Burritt, R. (2014), "Measuring and managing sustainability performance of supply chains: review and sustainability supply chain management framework", Supply Chain Management: An International Journal, Vol. 19 No. 3, pp. 232-241.

Schmitt, E., Galli, F., Menozzi, D., Maye, D., Touzard, J.M., Marescotti, A., Six, J. and Brunori, G. (2017), "Comparing the sustainability of local and global food products in Europe", Journal of Cleaner Production, Vol. 165, pp. 346-359.

Silvestre, B.S. (2015), "Sustainable supply chain management in emerging economies: environmental turbulence, institutional voids and sustainability trajectories", International Journal of Production Economics, Vol. 167, pp. 156-169.

Sousa, R. and Voss, C.A. (2008), "Contingency research in operations management practices", Journal of Operations Management, Vol. 26 No. 6, pp. 697-713.

Taticchi, P., Tonelli, F. and Pasqualino, R. (2013), "Performance measurement of sustainable supply chains: a literature review and a research agenda", International Journal of Productivity and Performance Management, Vol. 62 No. 8, pp. 782-804.

Trienekens, J.H., Wognum, P.M., Beulens, A.J.M. and vander Vorst, J.G.A.J. (2012), "Transparency in complex dynamic food supply chains", Advanced Engineering Informatics, Vol. 26, pp. 55-65.

Valkokari, K., Valkokari, P., Palomäki, K., Uusitalo, T., Reunanen, M., Macchi, M., Rana, P. and Prasanna Liyanage, J. (2014), "Road-mapping the business potential of sustainability within the European manufacturing industry", Foresight, Vol. 16 No. 4, pp. 360-384.

Vanegas, J.A. (2003), "Environment roadmap and principles for built sustainability", Environmental Science and Technology, Vol. 37, pp. 5363-5372.

Varsei, M., Soosay, C., Fahimnia, B. and Sarkis, J. (2014), "Framing sustainability performance of supply chains with multidimensional indicators", Supply Chain Management: An International Journal, Vol. 19 No. 3, pp. 242-257.

Voss, C., Tsikriktsis, N. and Frohlich, M. (2002), "Case research in operations management", International Journal of Operations and Production Management, Vol. 22 No. 2, pp. 195-219.

Waage, S.A. (2007), "Re-considering product design: a practical 'road-map' for integration of sustainability issues", Journal of Cleaner Production, Vol. 15 No. 7, pp. 638-649.

Wolf, J. (2014), "The relationship between sustainable supply chain management, stakeholder pressure and corporate sustainability performance", Journal of Business Ethics, Vol. 119 No. 3, pp. 317-328.

Yakovleva, N. (2007), "Measuring the sustainability of the food supply chain: a case study of the UK", Journal of Environmental Policy and Planning, Vol. 9 No. 1, pp. 75-100.

Yin, R.K. (2009), Case Study Research: Design and Methods, 4th ed., Sage Publications, Thousand Oaks, CA.

\section{Corresponding author}

Verónica León Bravo can be contacted at: veronica.leon@polimi.it 


\section{Appendix}

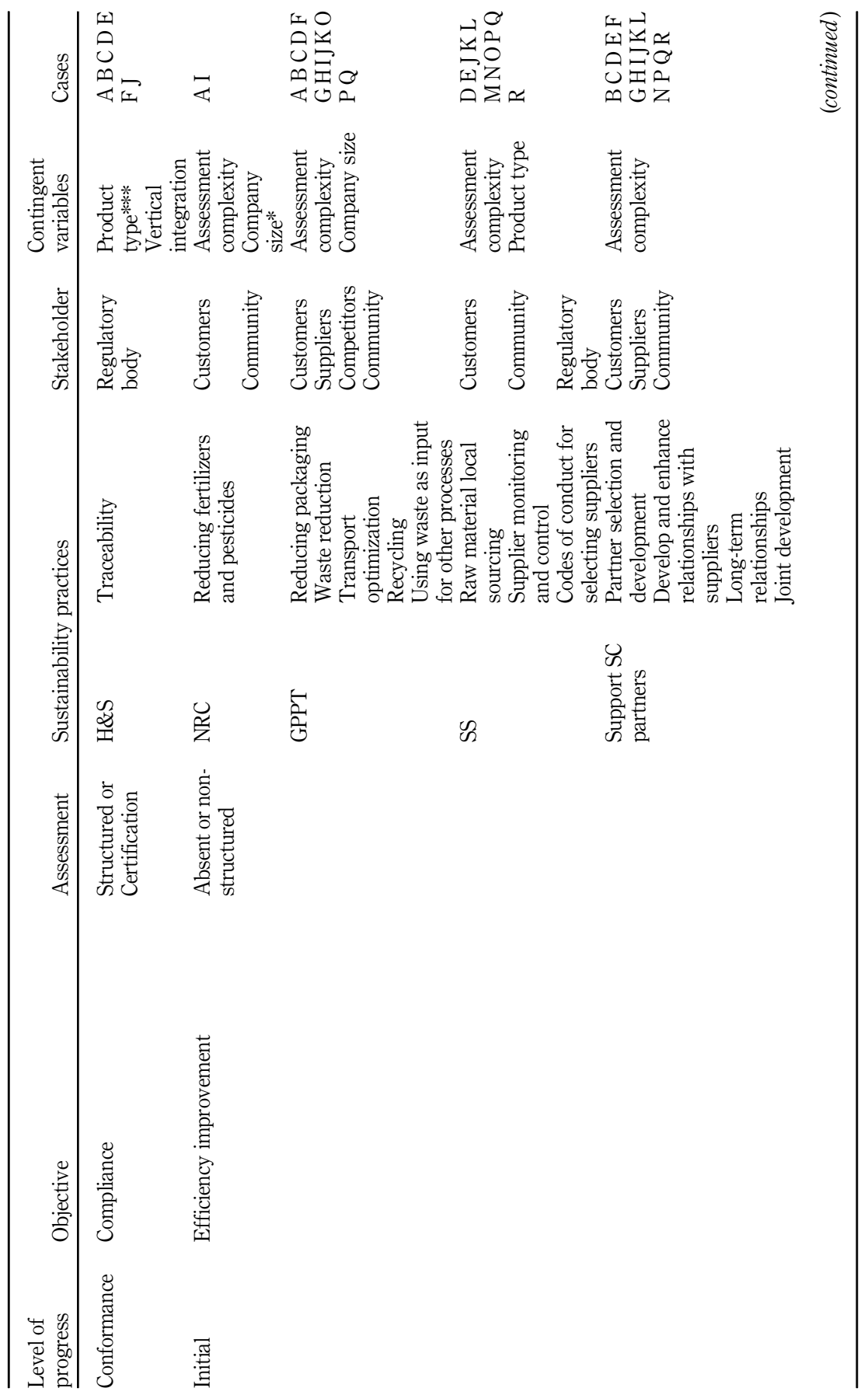

Roadmap for sustainability assessment in food SC

217

Table A1. Levels of progress in the roadmap, stakeholder and contingency variables related (Detail) 


\section{BFJ \\ 123,13}

$\underline{218}$

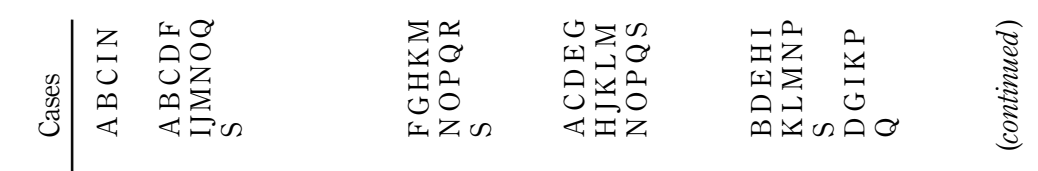

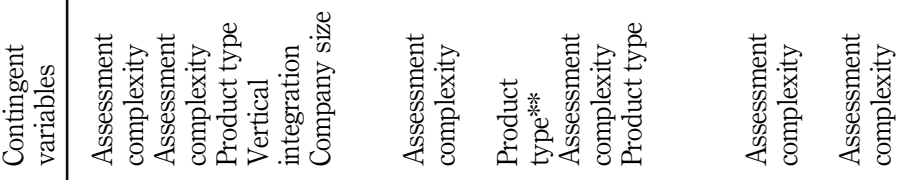

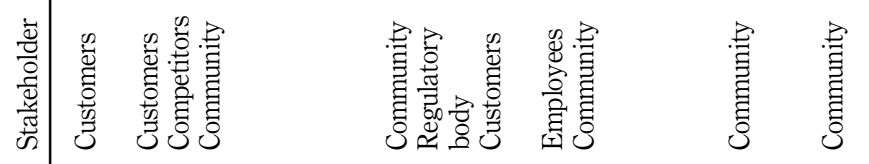

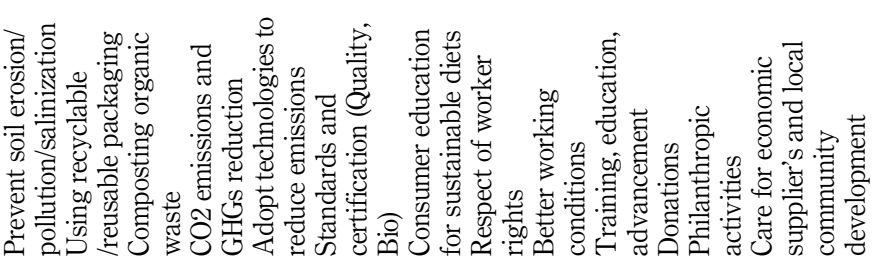

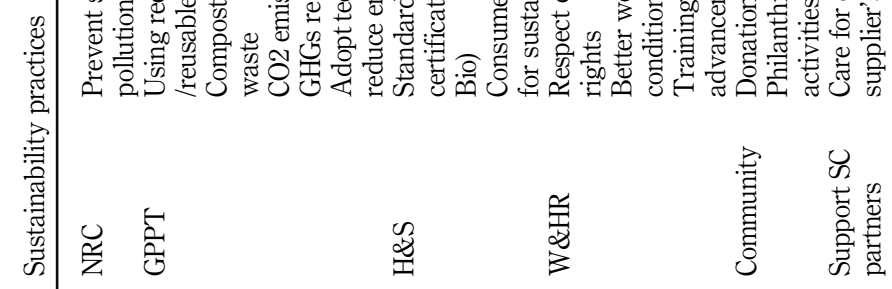

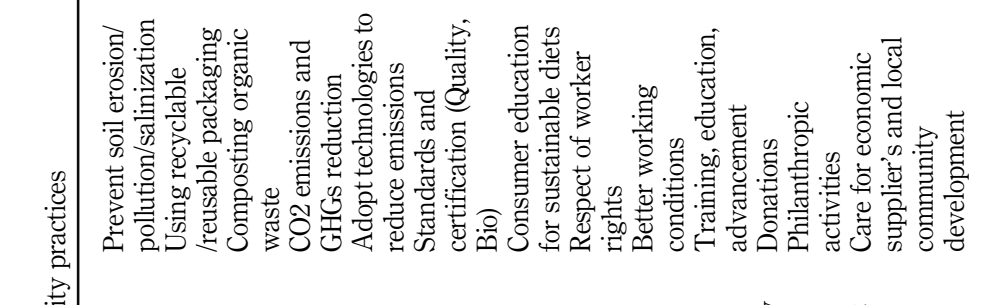

Table A1. 


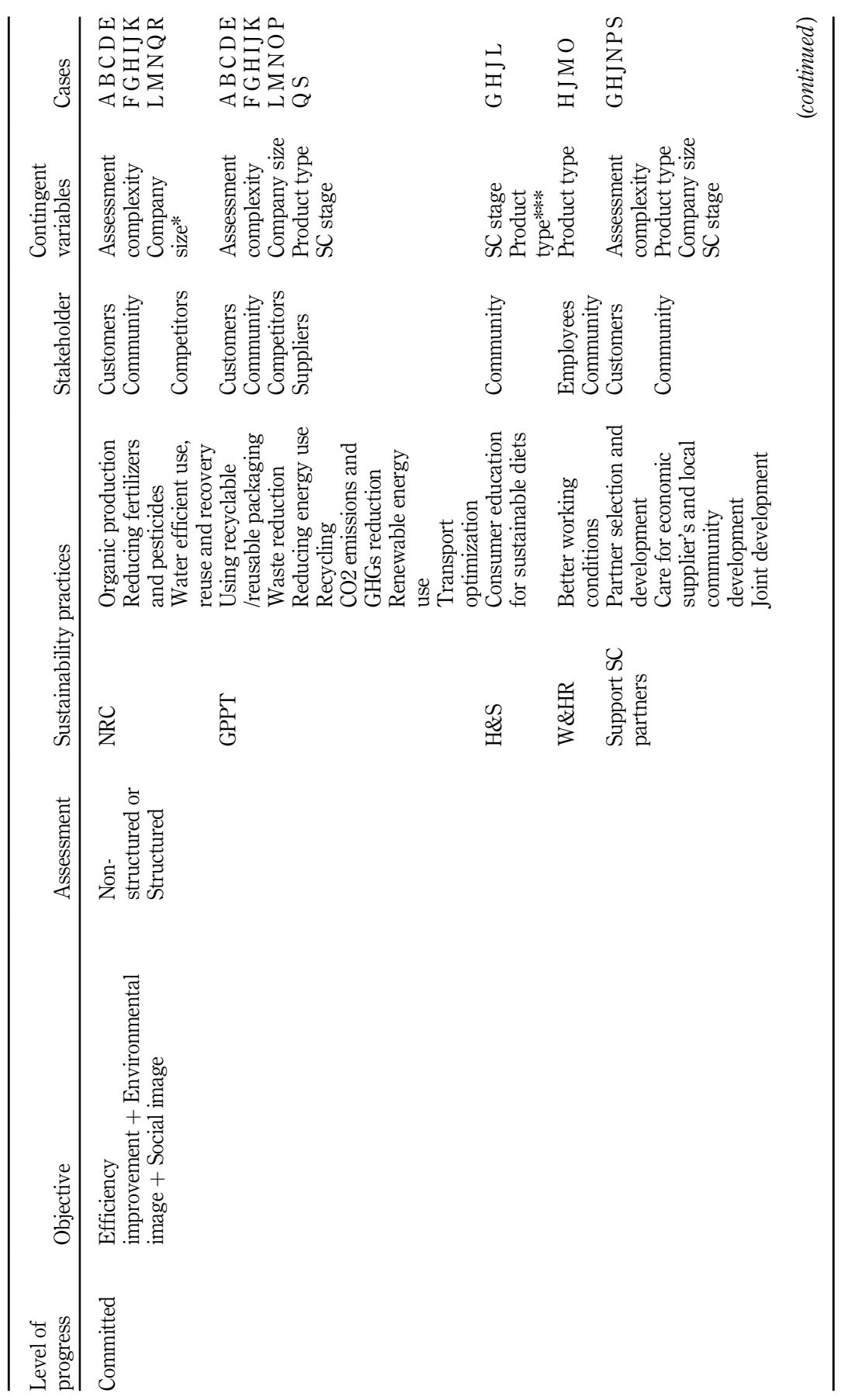

Roadmap for sustainability assessment in food SC

219

Table A1. 


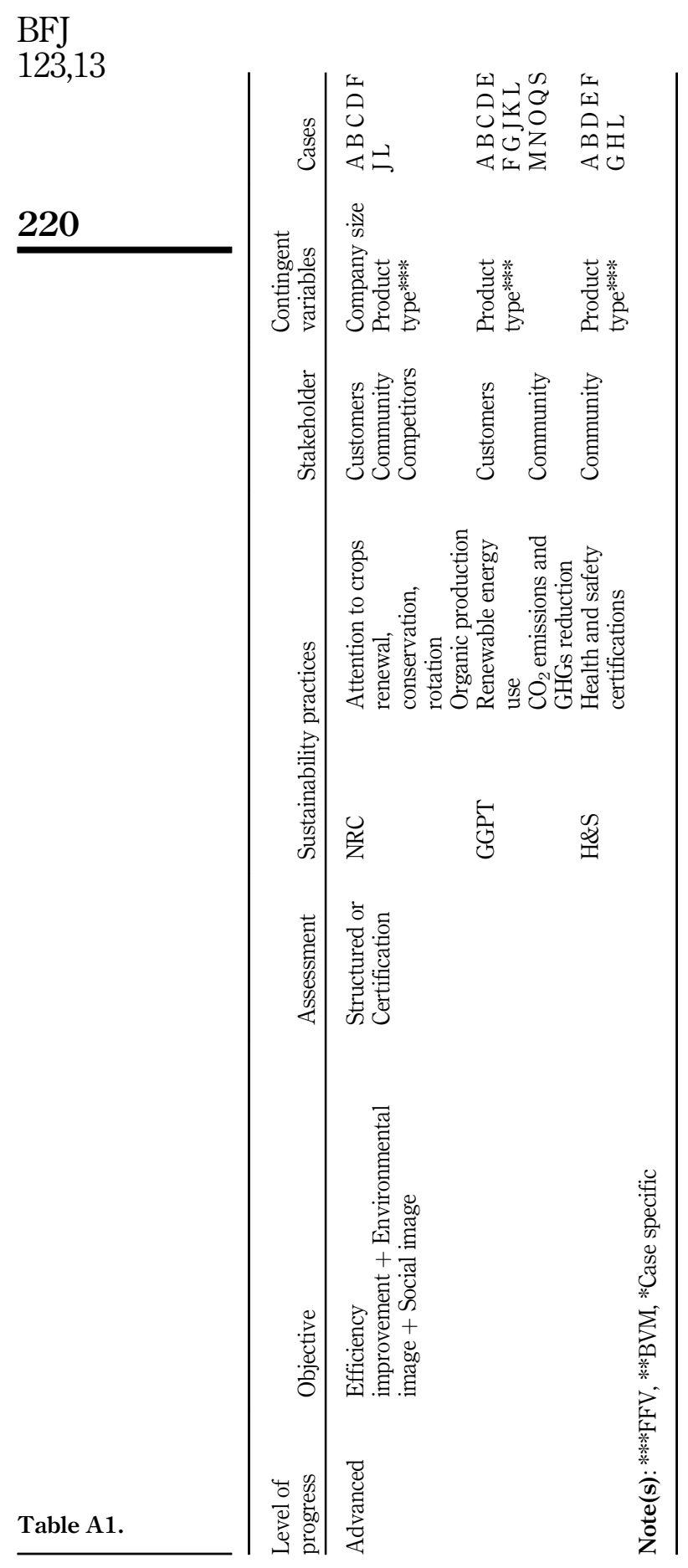

